(c) American Dairy Science Association, 2006.

\title{
Endogenous Production and Elevated Levels of Long-Chain n-3 Fatty Acids in the Milk of Transgenic Mice
}

\author{
B. T. Kao, K. A. Lewis, E. J. DePeters, and A. L. Van Eenennaam ${ }^{1}$ \\ Department of Animal Science, University of California, Davis 95616
}

\section{ABSTRACT}

N-3 Polyunsaturated fatty acids (n-3 PUFA) are important for the normal development and functioning of all organisms. Mammals lack the n-3 fatty acid desaturase required for the synthesis of $\alpha$-linolenic acid (18:3n3 ), and are therefore dependent on dietary sources to obtain this essential fatty acid. Currently, the richest source of dietary long-chain n-3 PUFA, eicosapentaenoic acid (20:5n-3) and docosahexaenoic acid (22:6n-3), are triacylglycerides extracted from rapidly declining marine resources. The nematode Caenorhabditis elegans synthesizes a wide range of PUFA and possesses the only known example of an n-3 fatty acid desaturase enzyme in the animal kingdom. Transgenic mice expressing the $C$. elegans $\mathrm{n}-3$ desaturase under the control of the lactationinduced goat $\beta$-casein mammary gland promoter were generated via pronuclear microinjection. Significant increases in n-3 PUFA, decreases in n-6 PUFA, and an overall decrease in the $n-6: n-3$ PUFA ratio were observed in the milk produced by transgenic mice. Neonate mice consuming milk from transgenic females accumulated increased levels of docosahexaenoic acid in their brains. This transgenic model may provide useful information to address some basic questions of neonatal nutrition, and demonstrates one of the steps that would be required to increase the n-3 PUFA content of milk and dairy products endogenously. Increasing the proportion of $n$ 3 PUFA in milk fat would help to improve the nutritional composition of an important component of the North American diet.

Key words: polyunsaturated fatty acid, n-3, fatty acid desaturase, transgenic

\section{INTRODUCTION}

Polyunsaturated fatty acids (PUFA) are fatty acids, usually of 18 carbons or more in length, with 2 or more double bonds. Polyunsaturated fatty acids can be divided into 2 main families, $n-3$ and $n-6$, depending on the

Received September 21, 2005.

Accepted March 11, 2006.

${ }^{1}$ Corresponding author: alvaneenennaam@ucdavis.edu position of the double bond relative to the methyl end of the fatty acid molecule. Numerous studies have demonstrated that n-3 PUFA are an important component of cellular structures and their inclusion in the diet provides a variety of health benefits, including improved brain and retinal development, and reduced risk of coronary heart disease and type II diabetes (Connor, 2000). Because vertebrates lack the n-3 fatty acid desaturase responsible for synthesizing n-3 PUFA, and because n3 and n-6 PUFA are not interconvertible in mammals, n-3 PUFA must be obtained from dietary sources. As a result of the increased consumption of vegetable oils rich in n-6 fatty acids, and the reduced consumption of fish and other foods rich in n-3 fatty acids, typical Western diets contain n-6:n-3 PUFA ratios that are greater than 10 (Simopoulos, 2004). Health studies suggest that a dietary n-6:n-3 PUFA ratio closer to 5 would be more favorable for cardiovascular well-being (Simopoulos, 1999). Proportional levels of $n-6$ and n-3 fatty acids in the diet promote a balanced interaction between the often antagonistic physiological effects of $n-6$ and $n-3$ products.

One of the challenges faced when trying to increase the consumption of long-chain n-3 PUFA in Western diets is that many consumers cannot tolerate the taste of fish and hence refuse to increase their fish consumption. Additionally, there are concerns about pollutants (Hites et al., 2004) and the adequacy of the current fish-based supply of these important fatty acids (Pauly et al., 2002; Myers and Worm, 2003). Milk and dairy products remain important dietary sources of nutrients in Western diets, and epidemiological studies suggest that milk and milk products fit well into a healthy eating pattern emphasizing fruits and vegetables (Pfeuffer and Schrezenmeir, 2000). The acyl lipids that comprise bovine milk fat contain a large number of different fatty acids and represent one of the most complex naturally occurring fats, but this observation must be set against the much-repeated generalization that milk fat is rich in saturated fatty acids. The typical fatty acid composition of bovine milk consists of 5\% PUFA, 70\% saturated fatty acids, and $25 \%$ monounsaturated fatty acids and contains little n3 PUFA (Grummer, 1991). Increasing the proportion of n-3 PUFA in milk fat would help to improve the nutri- 
tional composition of an important component of the North American diet. Milk is a particularly attractive target for n-3 PUFA augmentation because milk fat is dispersed in extremely small micelles, which improves the absorption and bioavailability of lipid-soluble compounds, including n-3 PUFA (Visioli et al., 2000).

The free-living nematode Caenorhabditis elegans is able to synthesize $\alpha$-linolenic acid (ALA, 18:3n-3) by virtue of possessing the only known example of an n-3 desaturase enzyme in the animal kingdom. This endogenous n-3 fatty acid desaturase recognizes a range of 18and 20-carbon n-6 substrates (Spychalla et al., 1997). Constitutive expression of the $C$. elegans n-3 desaturase under the control of the chicken $\beta$-actin promoter in transgenic mice was found to significantly increase the proportion of n-3 PUFA in total lipids of muscle, milk, brain, heart, erythrocytes, liver, lung, and spleen relative to control mice (Kang et al., 2004). We were interested in directing the expression of this transgene to the mammary gland during lactation as an approach to producing milk with elevated levels of n-3 fatty acids, while avoiding dramatic whole-animal fluctuations in the $n-6: n-3$ ratio. The goat $\beta$-casein promoter has been found to direct transgene expression primarily in the lactating mammary gland of transgenic mice (Roberts et al., 1992). The objectives of this study were to report on the fatty acid composition of the milk produced by transgenic mice expressing the $\mathrm{n}-3$ fatty acid under the control of the goat $\beta$-casein promoter, and to further report on the effects that consumption of transgenic milk had on pup brain fatty acid composition.

\section{MATERIALS AND METHODS}

\section{Desaturase Expression Vector and Production of Transgenic Mice}

The coding sequence of the C. elegans n-3 fatty acid desaturase (fat-1) gene (GenBank accession number L41807) was PCR amplified from pCE8 (Spychalla et al., 1997) with $\mathrm{n}-3$ desaturase forward 5'GTCGACCAT GGTCGCTCATTCCTCAG3' and reverse 5'GTCGACT TACTTGGCCTTTGCCTTC3' primers and cloned into pCR2.1 (Invitrogen, Carlsbad, CA). Following sequence verification, the coding sequence was isolated via digestion with SalI, gel purified, and subcloned into the XhoI site in the $\mathrm{pBC} 1$ milk expression vector (Invitrogen). This expression vector contains the goat $\beta$-casein promoter that targets gene expression almost exclusively to the mammary epithelial cells of the mammary gland during late pregnancy and lactation (Roberts et al., 1992). The resulting construct, the $n-3$ desaturase vector (Figure 1), was purified using the Qiagen Plasmid EndoFree Maxi Kit (Qiagen, Valencia, CA), subsequently digested with SalI and NotI restriction enzymes, and elec-

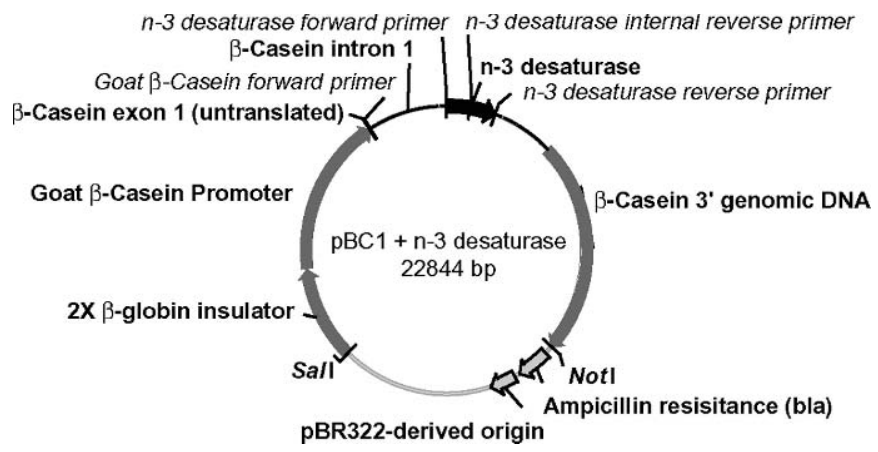

Figure 1. The vector used to create the transgenic mice expressing the Caenorhabditis elegans n-3 desaturase in the lactating mammary gland.

trophoresed on a $0.8 \%$ agarose gel to separate the $\beta$ casein promoter, $\mathrm{n}-3$ desaturase coding sequence, and $\beta$-casein 3 ' genomic sequences from the bacterial plasmid sequences. The resulting 16,967-bp fragment was isolated, purified using the ELUTRAP system with BT1 and BT2 membranes (Schleicher\&Schuell, Keene, NH), and used to produce transgenic mice $(\mathrm{C} 57 / \mathrm{BL} 6 \times \mathrm{DBA})$ by pronuclear microinjection using standard techniques (Gutierrez et al., 1996).

Mouse toe and tail clips from potential transgenic founders were each added to $100 \mu \mathrm{L}$ of lysis buffer [10 $\mathrm{m} M$ Tris-HCl, $\mathrm{pH}$ 8.0, $50 \mathrm{mM} \mathrm{KCl}, 20 \mu \mathrm{g}$ of proteinase K (EM Science, Darmstadt, Germany), 0.5\% Nonidet P40 substitute (Calbiochem, San Diego, CA), and 0.5\% Tween] and incubated at $55^{\circ} \mathrm{C}$ for $3 \mathrm{~h}$, agitating every $1 \mathrm{~h}$. Toe and tail samples were then heated to $95^{\circ} \mathrm{C}$ for $10 \mathrm{~min}$ to denature the proteinase $\mathrm{K}$, and DNA in the lysate was used as a template for PCR using the n3 desaturase forward and reverse primers. Transgenic founders were identified by the presence of a 1,444-bp PCR product and were used to establish transgenic lines through backcrossing with the C57/BL6 inbred mouse strain.

\section{Milk Fatty Acid Analysis}

Heterozygous transgenic and null (control) full-sib females were bred and maintained on Purina 5015 mouse chow [11\% total fat: $30 \%$ saturated fatty acids, $39 \%$ oleic acid (18:1), 28\% linoleic acid (LA, 18:2n-6), 0.7\% ALA, 0.15\% arachidonic acid (ARA, 20:4n-6); Ralston Purina Co., St. Louis, MO] during gestation and postpartum. Triplicate samples of milk were collected from transgenic and control females during peak lactation (d 8, 10, and 12) postpartum. Frozen milk samples were thawed in cold water, heated to $80^{\circ} \mathrm{C}$, and held for $1.5 \mathrm{~min}$ to deactivate lipase activity. The lipase-deactivated milk was extracted with chloroform:methanol (2:1) according to the 
method of Folch et al. (1957). Following centrifugation, the lower chloroform layer was transferred to a glass tube and taken to dryness under a stream of nitrogen, resuspended in $2 \mathrm{~mL}$ of hexane, and introduced onto a Sep-Pak silica cartridge (WAT051900; Waters, Milford, MA) that had previously been prepared by rinsing with $20 \mathrm{~mL}$ of chloroform. The nonpolar lipids (triacylglycerides) were eluted with four $10-\mathrm{mL}$ aliquots of hexane:ethyl ether (1:1) and collected in glass 50-mL tubes, dried down under a stream of nitrogen at $60^{\circ} \mathrm{C}$, and resuspended in $2 \mathrm{~mL}$ of iso-octane. The polar lipids (phospholipids) were eluted from the cartridge with two 10$\mathrm{mL}$ aliquots of methanol followed by two $10-\mathrm{mL}$ aliquots of chloroform:methanol:water (3:5:2) and also collected in glass tubes, dried down under a stream of nitrogen, and finally resuspended in $1 \mathrm{~mL}$ of iso-octane (Bitman et al., 1984). The triacylglyceride fraction was methylated by adding $200 \mu \mathrm{L}$ of $3 \mathrm{M}$ potassium hydroxide in methanol, vortexing, and allowing it to stand at room temperature for $15 \mathrm{~min}$. Esters were washed and separated by the addition of $2 \mathrm{~mL}$ of saturated $\mathrm{NaCl}$ and 8.5 $\mathrm{mL}$ of deionized water. Tubes were shaken with a Burell wrist-action shaker (Burell, Pittsburgh, PA) for $10 \mathrm{~min}$, centrifuged at $500 \times \mathrm{g}$ for $10 \mathrm{~min}$, and aliquoted into 1.8$\mathrm{mL}$ gas chromatography vials. The phospholipid fraction was methylated similarly, except only half of the volumes of potassium hydroxide and downstream reagents were used, and a final evaporation step was included, followed by resuspension in $100 \mu \mathrm{L}$ of iso-octane to concentrate the sample. The methyl esters were then resolved using a Supelco 2560, 100-m capillary column (Supelco, Bellefonte, PA) with a 0.25 -mm inside diameter and a film thickness of $0.20 \mu \mathrm{m}$. Hydrogen was used as the carrier gas with a linear flow rate of $27 \mathrm{~cm} / \mathrm{s}$ and a head pressure of $225 \mathrm{kPa}$. A Hewlett-Packard 5890 gas chromatograph equipped with a flame-ionization detector and a 7673 auto injector (Hewlett-Packard, Palo Alto, CA) injected $1 \mu \mathrm{L}$ of sample that was subjected to a 1:100 split ratio. Injector and detector temperatures were set at $220^{\circ} \mathrm{C}$ and the column temperature was programmed at $75^{\circ} \mathrm{C}$ for $10 \mathrm{~min}$, increased to $175^{\circ} \mathrm{C}$ at $20^{\circ} \mathrm{C} /$ $\mathrm{min}$. and held for $29 \mathrm{~min}$, then increased to a final temperature of $225^{\circ} \mathrm{C}$ at $5^{\circ} \mathrm{C} / \mathrm{min}$ and held for $12 \mathrm{~min}$. Fatty acids were identified by comparison of retention times with known standards, including 18:1 (18:2, 20:4, 22:5)n6 fatty acids and 18:3 (20:5, 22:5, 22:6)n-3 fatty acids. The detector signal was integrated and quantified using Chrom Perfect Spirit software, version 5.5 (Justice Laboratory Software, Denville, NJ), and fatty acid concentrations were reported as percentages of the total fatty acid content.

\section{Transgene Analysis}

Transgene expression was analyzed by reverse transcription-PCR of RNA derived from the brain, heart, liver, muscle, mammary gland, and milk somatic cells collected from transgenic mice $10 \mathrm{~d}$ postpartum and from nontransgenic controls. Extraction of RNA was performed according to the single-step method of total RNA isolation (Chomczynski and Sacchi, 1987). To perform first-strand cDNA synthesis, the following components were added to a nuclease-free microfuge tube and incubated at $65^{\circ} \mathrm{C}$ for $5 \mathrm{~min}$ to remove the RNA secondary structure: 1 to $3 \mu \mathrm{g}$ of RNA, $1 \mu \mathrm{L}$ of $0.5 \mu \mathrm{g} / \mu \mathrm{L}$ oligo $(\mathrm{dT})_{20}$, $1 \mu \mathrm{L}$ of $10 \mathrm{~m} M$ deoxyribonucleotide triphosphate (dNTP) mix, and sterile water to $14 \mu \mathrm{L}$. The tube was then placed on ice for $1 \mathrm{~min}$. For first-strand synthesis of cDNA, the following were added to each tube: $4 \mu \mathrm{L}$ of $5 \times$ FirstStrand Buffer, $1 \mu \mathrm{L}$ of $0.1 M$ dithiothreitol, and $1 \mu \mathrm{L}$ of $(200 \mathrm{u} / \mu \mathrm{L})$ SuperScript III reverse transcriptase (Invitrogen). The reaction was incubated at $50^{\circ} \mathrm{C}$ for $60 \mathrm{~min}$, then heat inactivated at $70^{\circ} \mathrm{C}$ for $15 \mathrm{~min}$. The resulting cDNA was used as a template for PCR $\left(94^{\circ} \mathrm{C}\right.$ for $3 \mathrm{~min}$, 25 cycles of $94^{\circ} \mathrm{C}$ for $45 \mathrm{~s}, 57^{\circ} \mathrm{C}$ for $30 \mathrm{~s}$, and $72^{\circ} \mathrm{C}$ for $90 \mathrm{~s}$ ) using a goat $\beta$-casein exon 1 forward primer ( $5^{\prime}$ TCCATTCAGCTTCTCCTTCA3'), and an internal n-3 desaturase reverse primer (5'TTCCATGATGGCATTG CTT3'). These primers were designed to span the transgenic goat $\beta$-casein intron 1 (Figure 1) such that they would amplify a 634-bp product from correctly spliced mRNA vs. a 2,655-bp product from genomic DNA. As a positive control for expression of the endogenous $\beta$-casein gene in milk, intron-spanning mouse $\beta$-casein primers (5'GGTGAATCTCATGGGACAGC3', 5'GGTTG AGCAATAGGCTGGAT3') were used to confirm the presence of a 153-bp fragment from spliced mouse $\beta$ casein transcripts. The previously described n-3 desaturase forward and reverse primers were also used to confirm the presence of a full-length 1,444-bp n-3 desaturase coding sequence transcript in milk, whereas a 406-bp housekeeping gene positive control band was amplified from tissue-specific cDNA using mouse $\beta$-actin primers (5'GACGGCCAGGTCATCACTAT3', 5'AGTCCGCCTA GAAGCACTTG3').

\section{Pup Brain Fatty Acid Analysis}

To examine the postnatal effects of consuming the n-3enriched milk, the brain fatty acid composition of mouse pups nursing on transgenic dams was compared with that of pups raised on the milk from nontransgenic dams. Suckling pups $(\mathrm{n}=12)$ were killed at $15 \mathrm{~d}$ of age to allow for the collection of whole brains. Brain samples were homogenized with $0.5 \mathrm{~mL}$ of PBS, methylated with 2 $\mathrm{mL}$ of $2 \% \mathrm{HCl}$ in methanol at $90^{\circ} \mathrm{C}$ for $30 \mathrm{~min}$, cooled to room temperature, and neutralized with $10 \mathrm{~mL}$ of $6 \%$ $\mathrm{K}_{2} \mathrm{CO}_{3}$. The samples were vortexed, and $3 \mathrm{~mL}$ of hexane and $1 \mathrm{~mL}$ of water were added to the solution. The samples were then vortexed again and centrifuged at $525 \times$ 
$g$ for $5 \mathrm{~min}$. The top organic layer was removed and evaporated under nitrogen and resuspended in $100 \mu \mathrm{L}$ of iso-octane. One microliter of the sample split 100 times was analyzed by gas chromatography, as previously described.

\section{Statistical Analyses}

The milk and brain fatty acid compositional analysis data were compared using ANOVA. Differences in proportions of fatty acids were considered significant if $P<$ 0.05. The model used for milk fatty acid data was

$$
y_{i j k}=\mu+G_{i}+M(G)_{i j}+e_{i j k}
$$

where $y_{i j k}$ is the lipid response of the $k$ th replicate $(k=$ $1,2,3), \mu$ is the overall mean, $G_{i}$ is the genotype ( $i=1$, 2), $M(G)_{i j}$ is the individual mouse within the genotype $(j=1, \ldots, 5)$, and $e_{i j k}$ is the residual error.

To analyze the difference between transgenic and nontransgenic n-6:n-3 milk PUFA ratios [18:2n-6 (LA) + 20:4n-6 (ARA)]:[18:3n-3 (ALA) + 20:5n-3 (EPA, eicosapentaenoic acid) + 22:6n-3 (DHA, docosahexaenoic acid)], a hypothesis test of the difference between the 2 ratios was performed. The variance and covariance of the ratios were used to calculate the standard error of the difference between ratios (Cochran, 1977). A onetailed test hypothesis of the difference between the 2 ratios was performed using the calculated standard error: $R-R^{\prime} \pm 1.65 \times S E\left(R-R^{\prime}\right)$, where $R$ and $R^{\prime}$ represent the ratios being compared, $\mathrm{SE}\left(\mathrm{R}-\mathrm{R}^{\prime}\right)$ is the standard error of the difference between the two ratios, and $1.65=\mathrm{z}_{0.05}$.

\section{RESULTS}

Polymerase chain reaction genotyping of the toe and tail samples from potential founder pups revealed that 4 out of 14 potential founder pups were positive for the transgene. The triacylglyceride and phospholipid fractions of the milk lipids from triplicate samples collected from a total of 33 heterozygous transgenic ( 4 to 6 females per line) and full-sib null (control) females were analyzed by gas chromatography. No statistically significant changes were observed in the fatty acid composition of milk from 3 of the 4 transgenic lines as compared with milk from the nontransgenic controls (data not shown). One line did show a milk fatty acid phenotype, and all further work concentrated on this transgenic line. Figure 2 summarizes the data collected from triplicate milk samples from a "contemporary" group of 5 heterozygous transgenic and 3 null full-sib females bred at the same time and fed the same batch of Purina 5015 mouse chow. The proportions of n-6 LA and ARA decreased $(P<0.01)$
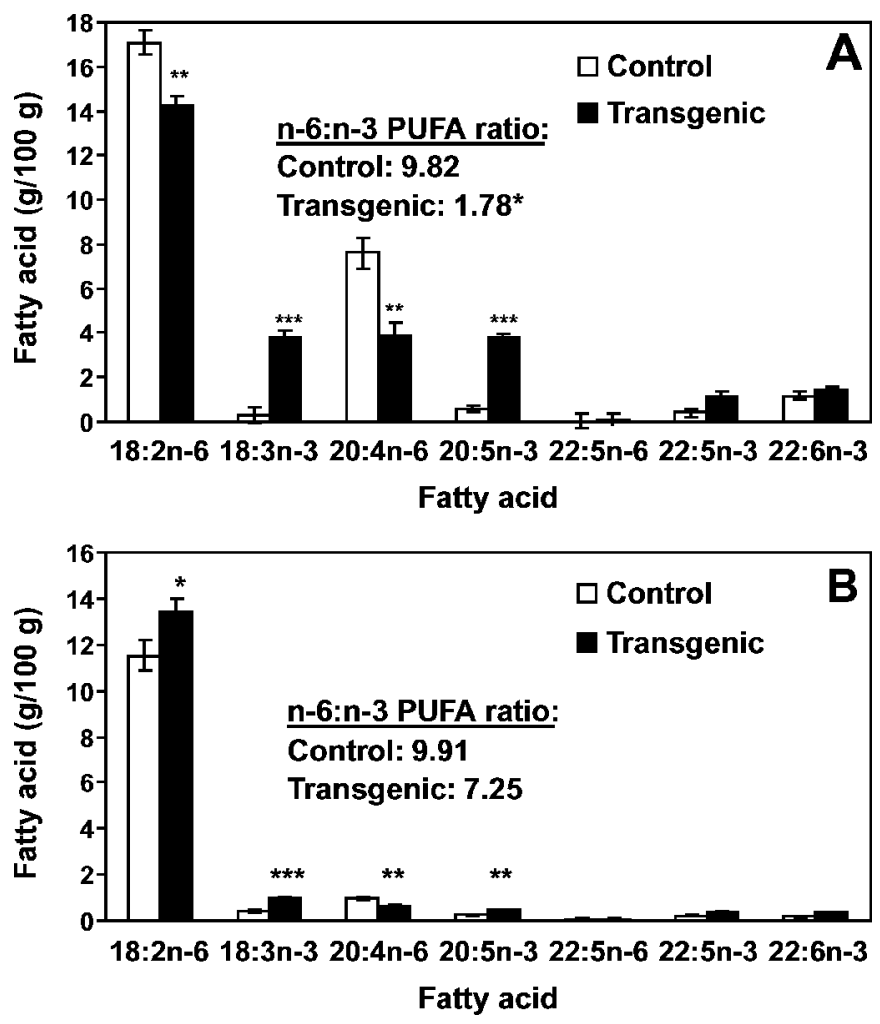

Figure 2. Fatty acid composition (g/100 g of fatty acids) as determined by gas chromatography of the (A) phospholipid and (B) triacylglyerol fraction of triplicate milk samples derived from full-sib nontransgenic $(\mathrm{n}=3)$ and transgenic mice $(\mathrm{n}=5)$ expressing the Caenorhabditis elegans $\mathrm{n}-3$ fatty acid desaturase gene under the control of the goat $\beta$-casein promoter. ${ }^{*} P<0.05$; $* * P<0.01$; $* * * P<0.001$. Error bars represent SEM. n-6:n-3 ratio $=$ [linoleic acid $(18: 2 n-6)+$ arachidonic acid (20:4n-6)]:[ $\alpha$-linolenic acid (18:3n-3) + eicosapentaenoic acid (20:5n-3) + docosahexaenoic acid (22:6n-3)] of milk fatty acids.

in the transgenic milk phospholipid fraction, whereas LA increased in the triacylglyceride fraction $(P<0.05)$. The proportions of the n-3 fatty acids ALA and EPA increased in both the triacylglyceride and phospholipid fractions $(P<0.01$ to 0.001$)$, although the magnitude of change was more pronounced in the phospholipid fraction (Figure 2). The n-6:n-3 ratios of the fatty acids in milk phospholipids were 9.82 and 1.78 in control and transgenic milk, respectively $(P<0.05)$.

The RNA extracted from the somatic cells present in the milk of heterozygous females confirmed the presence and correct mRNA processing of the n-3 desaturase transcript, whereas RNA from somatic cells in the milk of nontransgenic females revealed the presence of only the mouse $\beta$-casein transcript (Figure 3 ). The RNA extracted from the brain, heart, liver, mammary gland, and muscle tissue revealed the presence of the n-3 desaturase transcript in both mammary and muscle tissue but not in brain, heart, or liver (Figure 4), as noted elsewhere (Rob- 


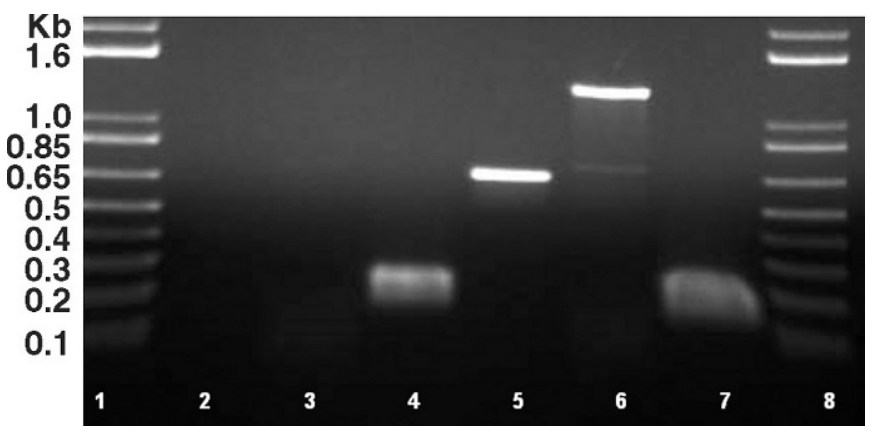

Figure 3. Reverse transcription-PCR analysis of somatic cells in milk from full-sib nontransgenic and transgenic mice expressing the Caenorhabditis elegans n-3 fatty acid desaturase gene under the control of the goat $\beta$-casein promoter. Lanes 1 and 8: $1 \mathrm{~kb}$ Plus bp Ladder (Invitrogen, Carlsbad, CA); lanes 2 to 4: control mouse milk; lanes 5 to 7: transgenic mouse milk; lanes 2 and 5: transgene intronspanning primers; lanes 3 and 6: n-3 desaturase primers; lanes 4 and 7: mouse $\beta$-casein intron-spanning primers. The $\mathrm{n}-3$ desaturase transcript (lane 5: 634-bp band; lane 6: 1,444-bp band) was detected only in the milk derived from transgenic mice. The mouse $\beta$-casein transcript (lanes 4 and 7: 153-bp band) was present in the milk from both transgenic and nontransgenic mice.

erts et al., 1992). Segregation ratios of offspring and Southern blot analysis were used to infer the number of insertion sites, transgene copy number, and orientation in the transgenic line (data not shown). Southern banding patterns revealed that 2 copies of the transgene integrated at a single insertion site in a tail-to-tail orientation. Identical banding patterns were observed in the founder and transgenic mice from subsequent generations. These observations, in conjunction with the fact that the transgene transmission rates from the founder and heterozygous progeny were not significantly different from 1:1, suggest that the transgene integrated at a single locus in the transgenic line.

Decreases in ARA and n-6 docosapentaenoic acid (DPA, 22:5; $P<0.001)$, and increases $(P<0.01$ to 0.05$)$ in LA, ALA, EPA, n-3 DPA were observed in the brains of 15-d-old pups nursed on transgenic dams as compared with the pups nursed on control dams (Figure 5).

\section{DISCUSSION}

Expression of the C. elegans n-3 fatty acid desaturase in the lactating mammary gland had a significant effect on milk fatty acid composition in 1 out of 4 lines of transgenic mice (Figure 2). The phospholipid fraction of transgenic mouse milk had decreased levels of $n-6$ PUFA and increased levels of n-3 PUFA, reflecting the known activities of the C. elegans n-3 desaturase (Spychalla et al., 1997). Levels of ALA and EPA were also increased in the milk triacylglyceride fraction, although the change was of a lesser magnitude. Unlike mammalian fatty acylcoenzyme A (CoA) desaturases, the C. elegans n-3 desa-

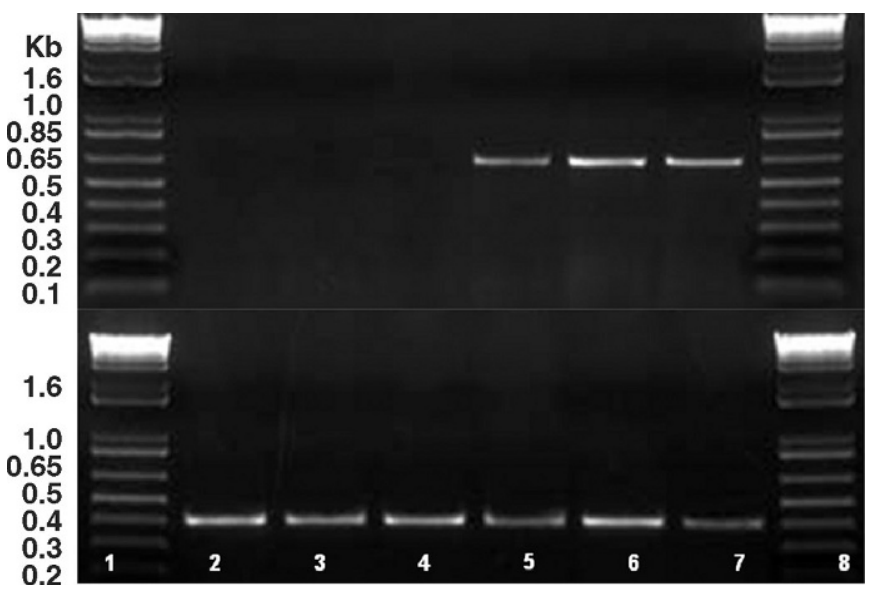

Figure 4. Reverse transcription-PCR analysis of tissues and milk obtained from a peak lactation heterozygous transgenic mouse expressing the Caenorhabditis elegans n-3 fatty acid desaturase gene under the control of the goat $\beta$-casein promoter. The top gel shows PCR products amplified with transgene-specific intron-spanning primers. The bottom gel shows PCR products amplified with mouse $\beta$-actin housekeeping primers. Lanes 1 and 8: $1 \mathrm{~kb}$ Plus bp Ladder (Invitrogen, Carlsbad, CA); lane 2: brain; lane 3: heart; lane 4: liver; lane 5: muscle; lane 6: mammary gland tissue; lane 7: milk. The $\mathrm{n}-$ 3 desaturase transcript (634-bp band) was detected in muscle, mammary gland, and milk somatic cells. The mouse $\beta$-actin transcript (406-bp band) was present in all samples.

turase is hypothesized to act on acyl lipids (Watts and Browse, 2002), and this may explain why it appeared to have a more immediate impact on phospholipid-bound acyl groups. The principal route of triacylglyceride biosynthesis involves the transfer of acyl-CoA to a glycerol backbone via the Kennedy pathway (Kennedy, 1961), although triacylglycerides can also be synthesized from the products of phospholipid hydrolysis. Results from this study suggest there was a limited progression of newly synthesized n-3 fatty acids from phospholipids to milk triacylglycerides. Although the expected decrease in ARA levels was seen in the triacylglyceride fatty acid pool, an unanticipated increase in LA levels was also observed. One possible explanation for this may be that there was an increased uptake of dietary LA for triacylglyceride biosynthesis in response to the $\mathrm{n}-3$ desaturasemediated disappearance of LA. It should be noted that the transgenic milk triacylglyceride LA mean was not statistically different from the control milk triacylglyceride LA mean when additional null females $(n=11)$ from the other 3 transgenic lines were included in the analysis (data not shown). This raises the possibility that the milk triacylglyceride LA mean for the null females from the transgenic line of interest may have been atypically low.

The milk phenotype observed in this study concurred with results obtained following the expression of the $C$. elegans n-3 desaturase in the cell culture. Constitutive 


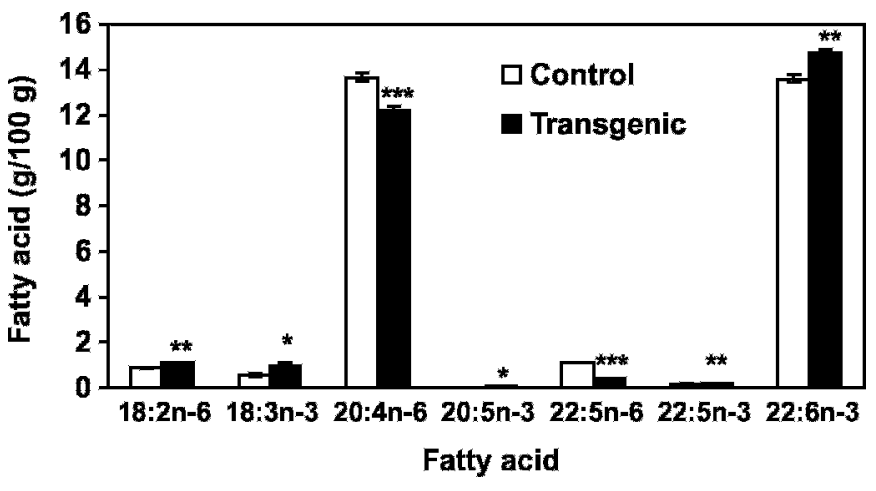

Figure 5. Fatty acid composition (g/100 g of fatty acids) as determined by gas chromatography of the total brain lipids derived from 15-d-old pups $(\mathrm{n}=12)$ nursed on either heterozygous transgenic dams expressing the Caenorhabditis elegans n-3 fatty acid desaturase gene under the control of the goat $\beta$-casein promoter or full-sib nontransgenic dams. $* P<0.05$; $* * P<0.01$; $* * * P<0.001$. Error bars represent SEM.

expression of the $\mathrm{n}-3$ desaturase in cardiac myocytes resulted in significant increases in the levels of $n-3$ fatty acids, and a decrease in the ratio of n-6:n-3 PUFA from 15:1 to $1: 1$ when comparing the total cellular lipids of the transduced cells to control cells (Kang et al., 2001). In an investigation from the same laboratory as the current study, the n-3 and n-6 desaturase genes were coexpressed in HC11 mouse mammary epithelial cells (Morimoto et al., 2005). Fatty acid composition of the cellular phospholipids from the transduced cells had decreased levels of oleic acid (18:1, presumably associated with the activity of the n- 6 desaturase), decreased levels of ARA, and increased levels of ALA and EPA associated with the activities of the n-3 desaturase. The cellular triacylglyceride fatty acid pool revealed similar patterns of change, but, as observed in the transgenic mouse milk of this study, fewer changes were effected by the acyllipid desaturase in the triacylglyceride fatty acid pool than those seen in the phospholipid fatty acid pool.

Constitutive expression of a codon-optimized C. elegans n-3 desaturase sequence in transgenic mice was previously reported to significantly increase the total milk lipid n-3 PUFA fatty acid content (Kang et al., 2004). That study did not examine the fatty acid composition of triacylglycerides and phospholipids separately. However, given that triacylglycerides make up approximately $99 \%$ of mouse milk lipids, it can be inferred that n-3 PUFA levels were elevated in the milk triacylglyceride fraction. That result can be contrasted with the current study, in which there was comparatively little change in the fatty acid composition and n-6:n-3 ratio of the milk triacylglycerides (Figure 1). This difference is most likely attributable to promoter choice. Constitutive expression of the $C$. elegans n-3 desaturase during the life of the transgenic mouse, as was done in the study by Kang et al. (2004), would continuously catalyze the production of $\mathrm{n}-3$ fatty acids in cellular phospholipids throughout the body. Over time, the turnover of phospholipids would result in these n-3 fatty acids becoming available as acyl-CoA or as phospholipid hydrolysis products for milk triacylglyceride biosynthesis. However, the promoter used in this study directed the expression of the n-3 desaturase only during late pregnancy and lactation (Roberts et al., 1992). There may not have been enough time for phospholipid turnover to supply appreciable quantities of the newly formed n-3 fatty acids for milk triacylglyceride biosynthesis. It should also be noted that the $n-3$ desaturase cDNA used to make the transgenic mice was the original C. elegans sequence; hence, it was not codon optimized for expression in a mammalian system. This may have inhibited the production of the transgenic protein and may have been one of the factors that contributed to the absence of a milk fatty acid phenotype in 3 of the 4 transgenic lines examined.

There are valid reasons to study both constitutive and tissue-specific expression of this gene. Future studies with transgenic mice will reveal whether adverse health effects are associated with dramatic fluctuations in the n-6:n-3 ratio. Such an outcome may be anticipated given that the ratio of $n-6: n-3$ PUFA influences steroid synthesis and the formation of eicosanoids such as prostaglandins, which are important cell-signaling molecules that are associated with reproductive performance (Abayasekara and Wathes, 1999; Robinson et al., 2002). It is also possible that the production of high levels of PUFA in milk or meat will have deleterious effects on flavor and shelf life, and so a weaker or tissue-specific promoter may be better suited to producing optimal levels of $n-3$ PUFA in animal products. Production of n-3 PUFA in ruminant milk would be more complicated than production in nonruminant milk. The reason for this is that dietary fatty acids are saturated in the rumen by biohydrogenation. Although mammary epithelial cells contain a stearoyl-CoA desaturase enzyme that can desaturate stearic acid (18:0) to form oleic acid (18:1), the endogenous production of $n-3$ PUFA in ruminant milk would require the expression of both an $\mathrm{n}-6$ fatty acid desaturase to convert oleic acid to LA and an n-3 fatty acid desaturase, as has been demonstrated in a cell culture (Morimoto et al., 2005).

Despite the fact that there was no significant difference in the n-6 DPA or DHA contents of transgenic vs. control milk, there was an elevated level of DHA in the brains of pups nursing on transgenic dams, and n-6 DPA in the brains of pups nursing on control dams (Figure 5). Docosahexaenoic acid is highly concentrated in cell membranes of the retina and brain, and it accumulates rapidly during the "brain growth spurt" of the last tri- 
mester of fetal life and the first $2 \mathrm{yr}$ of childhood (McCann and Ames, 2005). Dietary deficiency of n-3 PUFA results in a characteristic increase in n-6 DPA in brain phospholipids as a mechanism to maintain the total n-3 and n6 PUFA contents in the membrane phospholipids (Innis and Dyer, 2002). The n-3 desaturase transgenic mice may prove to be an interesting model to address questions related to the neonatal effects of including n-3 PUFA in postparturitional nutrition.

\section{CONCLUSIONS}

Results from this study demonstrate that transgenic expression of the C. elegans n-3 fatty acid desaturase in the mammary gland significantly altered the fatty acid profile of milk lipids. Although only modest increases in total milk n-3 PUFA were observed, there was a significant decrease in the n-6:n-3 ratio of milk phospholipids and an increase in the brain DHA content of pups consuming milk from transgenic dams. Mammary gland expression of $n-3$ desaturases may generate data of interest to human neonatal nutritional researchers, and would be one of the steps required for the production of land-based dairy products containing long-chain n3 PUFA.

\section{ACKNOWLEDGMENTS}

We thank Scott Taylor for technical assistance with the fatty acid analyses, Tom Famula for help with statistical analyses, and John Browse, Institute of Biological Chemistry, Washington State University, Pullman, Washington, for generously providing the C. elegans n3 desaturase cDNA. This research was supported by NIH grant 1R03HD047193-01 (to A.L.V.) and the University of California Davis Dairy Milk Components Laboratory.

\section{REFERENCES}

Abayasekara, D. R., and D. C. Wathes. 1999. Effects of altering dietary fatty acid composition on prostaglandin synthesis and fertility. Prostaglandins Leukot. Essent. Fatty Acids 61:275-287.

Bitman, J., D. L. Wood, N. R. Mehta, P. Hamosh, and M. Hamosh. 1984. Comparison of the phospholipid composition of breast milk from mothers of term and preterm infants during lactation. Am. J. Clin. Nutr. 40:1103-1119.

Chomczynski, P., and N. Sacchi. 1987. Single-step method of RNA isolation by acid guanidinium thiocyanate phenol chloroform extraction. Anal. Biochem. 162:156-159.

Cochran, W. 1977. Sampling Techniques. John Wiley \& Sons, New York, NY.
Connor, W. E. 2000. Importance of n-3 fatty acids in health and disease. Am. J. Clin. Nutr. 71:171S-175S.

Folch, J., M. Lees, and G.H. Sloane Stanley. 1957. A simple method for the isolation and purification of total lipides from animal tissues. J. Biol. Chem. 226:497-509.

Grummer, R. R. 1991. Effect of feed on the composition of milk fat. J. Dairy Sci. 74:3244-3257.

Gutierrez, A., H. M. Meade, P. Ditullio, D. Pollock, M. Harvey, R. Jimenez-Flores, G. B. Anderson, J. D. Murray, and J. F. Medrano. 1996. Expression of a bovine $\kappa$-CN cDNA in the mammary gland of transgenic mice utilizing a genomic milk protein gene as an expression cassette. Transgenic Res. 5:271-279.

Hites, R. A., J. A. Foran, D. O. Carpenter, M. C. Hamilton, B. A. Knuth, and S. J. Schwager. 2004. Global assessment of organic contaminants in farmed salmon. Science 303:226-229.

Innis, S. M., and R. A. Dyer. 2002. Brain astrocyte synthesis of docosahexaenoic acid from n-3 fatty acids is limited at the elongation of docosapentaenoic acid. J. Lipid Res. 43:1529-1536.

Kang, J. X., J. Wang, L. Wu, and Z. B. Kang. 2004. Transgenic mice: Fat-1 mice convert n-6 to n-3 fatty acids. Nature 427:504.

Kang, Z. B., Y. L. Ge, Z. H. Chen, J. Cluette-Brown, M. Laposata, A. Leaf, and J. X. Kang. 2001. Adenoviral gene transfer of Caenorhabditis elegans $\mathrm{n}-3$ fatty acid desaturase optimizes fatty acid composition in mammalian cells. Proc. Natl. Acad. Sci. USA 98:4050-4054.

Kennedy, E. P. 1961. Biosynthesis of complex lipids. Fed. Proc. 20:934-940.

McCann, J. C., and B. N. Ames. 2005. Is docosahexaenoic acid, an n3 long-chain polyunsaturated fatty acid, required for development of normal brain function? An overview of evidence from cognitive and behavioral tests in humans and animals. Am. J. Clin. Nutr. 82:281-295.

Morimoto, K. C., A. L. Van Eenennaam, E. J. DePeters, and J. F. Medrano. 2005. Hot topic: Endogenous production of n-3 and n-6 fatty acids in mammalian cells. J. Dairy Sci. 88:1142-1146.

Myers, R. A., and B. Worm. 2003. Rapid worldwide depletion of predatory fish communities. Nature 423:280-283.

Pauly, D., V. Christensen, S. Guenette, T. J. Pitcher, U. R. Sumaila, C. J. Walters, R. Watson, and D. Zeller. 2002. Towards sustainability in world fisheries. Nature 418:689-695.

Pfeuffer, M., and J. Schrezenmeir. 2000. Bioactive substances in milk with properties decreasing risk of cardiovascular diseases. Br. J. Nutr. 84(Suppl. 1):S155-S159.

Roberts, B., P. Ditullio, J. Vitale, K. Hehir, and K. Gordon. 1992. Cloning of the goat $\beta$-casein-encoding gene and expression in transgenic mice. Gene 121:255-262.

Robinson, R. S., P. G. Pushpakumara, Z. Cheng, A. R. Peters, D. R. Abayasekara, and D. C. Wathes. 2002. Effects of dietary polyunsaturated fatty acids on ovarian and uterine function in lactating dairy cows. Reproduction 124:119-131.

Simopoulos, A. P. 1999. Essential fatty acids in health and chronic disease. Am. J. Clin. Nutr. 70(3 Suppl.):560S-569S.

Simopoulos, A. P. 2004. Omega-6/omega-3 essential fatty acid ratio and chronic diseases. Food Rev. Int. 20:77-90.

Spychalla, J. P., A. J. Kinney, and J. Browse. 1997. Identification of an animal omega-3 fatty acid desaturase by heterologous expression in Arabidopsis. Proc. Natl. Acad. Sci. USA 94:1142-1147.

Visioli, F., P. Rise, E. Plasmati, F. Pazzucconi, C. R. Sirtori, and C. Galli. 2000. Very low intakes of n-3 fatty acids incorporated into bovine milk reduce plasma triacylglycerol and increase HDL-cholesterol concentrations in healthy subjects. Pharmacol. Res. 41:571-576.

Watts, J. L., and J. Browse. 2002. Genetic dissection of polyunsaturated fatty acid synthesis in Caenorhabditis elegans. Proc. Natl. Acad. Sci. USA 99:5854-5859. 